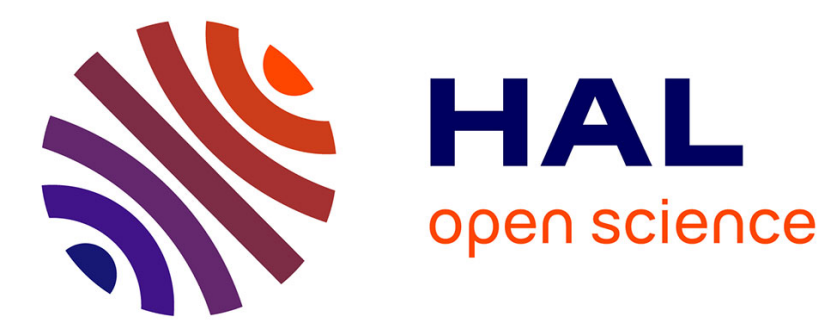

\title{
Effects of lymphotoxin-alpha gene and galectin-2 gene polymorphisms on inflammatory biomarkers, cellular adhesion molecules and risk of coronary heart disease
}

Folkert W Asselbergs, Jennifer K Pai, Kathryn M Rexrode, David J Hunter, Eric B Rimm

\section{To cite this version:}

Folkert W Asselbergs, Jennifer K Pai, Kathryn M Rexrode, David J Hunter, Eric B Rimm. Effects of lymphotoxin-alpha gene and galectin-2 gene polymorphisms on inflammatory biomarkers, cellular adhesion molecules and risk of coronary heart disease. Clinical Science, 2006, 112 (5), pp.291-298. 10.1042/CS20060200 . hal-00479339

\section{HAL Id: hal-00479339 \\ https://hal.science/hal-00479339}

Submitted on 30 Apr 2010

HAL is a multi-disciplinary open access archive for the deposit and dissemination of scientific research documents, whether they are published or not. The documents may come from teaching and research institutions in France or abroad, or from public or private research centers.
L'archive ouverte pluridisciplinaire HAL, est destinée au dépôt et à la diffusion de documents scientifiques de niveau recherche, publiés ou non, émanant des établissements d'enseignement et de recherche français ou étrangers, des laboratoires publics ou privés. 
Effects of lymphotoxin- $\alpha$ gene and galectin 2 gene polymorphisms on inflammatory biomarkers, cellular adhesion molecules, and risk

of coronary heart disease

\section{Folkert W. ASSELBERGS* $\|$, Jennifer K. PAI $\uparrow$, Kathryn M. REXRODE $\$$, David}

\section{J. HUNTER* $* \S$, and Eric B. RIMM* $* \S$}

*Department of Nutrition, Harvard School of Public Health, 665 Huntington Avenue, 02115, Boston, Massachusetts, USA

$\dagger$ Department of Epidemiology, Harvard School of Public Health, 677 Huntington Avenue, 02115, Boston, Massachusetts, USA

t Division of Preventive Medicine, Department of Medicine, Brigham \& Women’s Hospital, 900 Commonwealth Avenue, 02215, Boston, Massachusetts, USA

$\S$ Channing Laboratory, Department of Medicine, Brigham \& Women’s Hospital, and Harvard Medical School, 181 Longwood Avenue, 02115, Boston, Massachusetts, USA

|| Department of Cardiology, University Medical Center Groningen, P.O. Box 30001, Hanzeplein 1, 9700 RB, Groningen, The Netherlands

Short title: Lymphotoxin alpha gene polymorphisms and CHD

Key words: Epidemiology, Cohort, Genetic association study, Inflammation, Myocardial infarction, and Heart.

Abbreviations: LTA, Lymphotoxin $\alpha$; LGALS2, galectin 2; CHD, coronary heart disease; CRP, C-reactive protein; IL, interleukin; sTNF-R, soluble tumor necrosis factor receptor, VCAM-1, vascular cell adhesion molecule 1 .

Correspondence: Dr. Folkert W. Asselbergs (email fwasselbergs@hotmail.com). 


\begin{abstract}
The proinflammatory cytokine lymphotoxin- $\alpha$ (LTA) has multiple functions in regulation of the immune system and may contribute to inflammatory processes leading to coronary heart disease (CHD). The aim of this study was to investigate whether the common T26N and A252G polymorphisms of the LTA gene and the C3279CT polymorphism of the galectin 2 (LGALS2) gene, which affects LTA secretion, are associated with inflammatory parameters and cell adhesion molecules and whether these polymorphisms are related to CHD in US women and men. We conducted a prospective nested case-control study within the Nurses' Health Study and Health Professionals Follow-Up Study. Among participants free of cardiovascular disease at baseline, 249 women and 266 men developed CHD during 8 and 6 years of follow-up respectively, and we matched controls 2:1 based on age and smoking. The LGALS2 gene variant was significantly associated with a decreased risk for CHD in women (Odds ratio [95\% confidence intervals]: 0.70 [0.50-0.97], $\mathrm{p}=0.03)$. In addition, the LGALS2 polymorphism was directly associated with $\mathrm{C}$-reactive protein levels in cases from both studies $(\mathrm{p}<0.05)$. The LTA gene polymorphisms were directly associated with levels of soluble tumor necrosis factor receptors and vascular cell adhesion molecule- 1 in both women and men with $\mathrm{CHD}(\mathrm{p}<0.05)$. However, no overall effect was demonstrated between LTA gene polymorphisms and risk for CHD.
\end{abstract}




\section{INTRODUCTION}

Inflammation plays an important role in the development and progression of atherosclerosis and is likely to play a critical role in the pathogenesis of plaque rupture which precedes a myocardial infarction[1]. The proinflammatory cytokine lymphotoxin- $\alpha$ (LTA or tumor necrosis factor- $\beta$ ) is found in atherosclerotic lesions[2] and may contribute to these processes. Further, LTA may also induce adhesion molecules and cytokines from vascular endothelial and smooth muscle cells[3]. A large-scale association study from the Japanese Osaka Acute Coronary Insufficiency Study Group identified functional single nucleotide polymorphisms (SNP's) within the LTA gene that were associated with risk of myocardial infarction (LTA T26N and LTA A252G)[4]. Among these SNPs, the LTA T26N polymorphism induced an almost twofold higher expression of Eselectin and vascular cell adhesion molecule-1 (VCAM-1) in cultured human coronary artery smooth muscle cells and the presence of LTA A252G polymorphism was associated with a 1.5 fold greater transcriptional activity of LTA[4]. The LTA and tumor necrosis factor- $\alpha$ (TNF- $\alpha)$ genes are in significant linkage disequilibrium and are situated close to each other within the human leukocyte antigen (HLA) class III cluster on the short arm of chromosome 6.

Several other studies have examined the association between LTA gene polymorphisms and coronary heart disease (CHD), but these studies were based on identification of prevalent cases and results were inconsistent [5-10]. In addition, genotype distribution in the original study by Ozaki et al. deviated from Hardy-Weinberg equilibrium in the control group [4]. A prospective longitudinal study is needed to investigate the association between LTA gene polymorphisms and CHD. Furthermore, the relation between LTA gene polymorphisms and plasma levels of inflammatory markers and cell adhesion molecules are unknown.

Recently, the Japanese Osaka Acute Coronary Insufficiency Study Group identified galectin-2 protein as a regulator of LTA protein secretion and therefore also potentially important in modifying the degree of inflammation[3]. Both LTA and galectin-2 are expressed in smooth 
muscle cells and macrophages in the intima of atherosclerotic lesions of the coronary artery. Further, the functional SNP (C3279T) in the galectin 2 (LGALS2) gene may be inversely associated with risk of myocardial infarction[3]. No study has yet replicated these results in a prospective design.

We hypothesize that the common T26N and A252G polymorphisms of the LTA gene and the C3279CT polymorphism of the LGALS2 gene are associated with circulating inflammatory markers and cell adhesion molecules (i.e. C-reactive protein, interleukin-6, soluble TNF receptors 1 and 2, VCAM-1, and E-selectin) and we aim to investigate whether these polymorphisms are related to CHD in a large nested case-control study among US women and men.

\section{METHODS}

\section{Study population}

We conducted a prospective nested case-control study within the Nurses' Health Study (NHS) and Health Professionals Follow-Up Study (HPFS). Among participants free of cardiovascular disease at baseline, 249 women and 266 men developed nonfatal myocardial infarction or fatal CHD during 8 and 6 years of follow-up, respectively. As a secondary end point, we additionally identified 564 men who had coronary artery bypass graft surgery (CABG) or percutaneous transluminal coronary angioplasty (PTCA) during follow-up. Myocardial infarction was confirmed using World Health Organization criteria. Deaths were identified from state vital records and the National Death Index or reported by subjects' next of kin or the postal system. Fatal CHD was confirmed by hospital records or on autopsy, or if CHD was listed as the cause of death on the death certificate, if it was the underlying and most plausible cause, and if evidence of previous CHD was available. Confirmation of CABG/PTCA was based on self-report only. The study protocol was approved by the institutional review board of the Brigham and Women's 
Hospital and the Harvard School of Public Health Human Subjects Committee review board; all participants provided informed consent.

Controls were selected 2:1 matched on age, smoking, and month of blood draw. In addition, female controls were matched on fasting status. Biomarkers were measured for nonfatal MI and fatal CHD cases and their controls only (the set of CABG/PTCA cases and controls did not have available plasma biomarkers).

\section{Laboratory methods}

C-reactive protein (CRP) concentrations were determined using an immunoturbidimetric high sensitivity assay using reagents and calibrators from Denka Seiken (Niigata, Japan) with assay day-to-day variability between 1 and 2\%. Levels of interleukin-6 (IL-6), soluble tumor necrosis factor receptors (sTNF-R1 and sTNF-R2), VCAM-1, and E-selectin were measured by enzymelinked immunosorbent assays from R\&D Systems (Minneapolis, MN, USA)[11], which have a day-to-day variability of 3.5-9.0\%. HDL, and directly obtained LDL cholesterol were measured using standard methods with reagents from Roche Diagnostics (Indianapolis, IN, USA) and Genzyme (Cambridge, MA, USA).

\section{Genotyping of polymorphisms}

DNA was extracted from the buffy coat fraction of centrifuged blood using the QIAmp Blood Kit (Qiagen). We studied two SNP's in the LTA gene on chromosome 6p21 (HLA cluster): the LTA T26N (rs1041981) in exon 3 (resulting in the amino-acid substation Thr26Asn) and LTA A252G (rs909253) in intron 1. In addition, we genotyped the C3279T (rs7291467) polymorphism in intron 1 of LGALS2 gene on chromosome 22q using Taqman single nucleotide polymorphism allelic discrimination by means of an ABI 7900HT (Applied Biosystems). Primer and probe sequences are available on request. 


\section{Statistical analysis}

Continuous data are reported as mean (standard deviation) or median (interquartile range) if the data was skewed. Categorical data are presented as per group percentages. Differences between subgroups were evaluated by Student's $t$-test for the normally distributed continuous variables or by the Mann-Whitney test if data were skewed. Differences in genotype frequencies and other categorical data between cases and controls were compared with the $\chi^{2}$ test or Fisher's exact test. Consistency of genotype frequencies with the Hardy-Weinberg equilibrium was tested using a chi-squared goodness-of-fit test on a contingency table of observed versus expected genotype frequencies in cases and controls. Genotype-phenotype associations were examined with additive, dominant and recessive models using multivariate logistic regression analyses. Odds ratios for the occurrence of CHD and their 95\% confidence intervals were calculated after adjustment for matching factors. Linear mixed models were used to investigate the age-adjusted association between genotypes and inflammatory markers. In addition, linear mixed models were used to investigate the gene-environment interaction between BMI and LTA and LGALS2 gene polymorphisms on inflammatory markers. All results were considered statistically significant if the two-sided p-value for the test statistic was less than or equal to the set type I error rate $(\alpha)$ of 0.05. No adjustment for multiple comparisons was performed because there were few statistical tests and there is good biological evidence that each of the biochemical systems being studied is functionally involved in regulating inflammatory status either directly or indirectly, suggesting the universal null hypothesis that is assumed for a Bonferroni-type correction does not apply to these data [12]. Analyses were performed using SAS 9.1 (SAS Institute Inc., Cary, NC, USA).

\section{RESULTS}




\section{Baseline characteristics}

The general characteristics of both the NHS as well as the HPFS, divided on the basis of cases and controls, are listed in table 1. Cases were more likely to have diabetes, hypertension, and a family history of myocardial infarction than matched controls. In addition, cases from both studies had significantly higher levels of LDL-cholesterol and lower levels of HDL-cholesterol. Women with CHD had a higher body mass index and higher levels of inflammatory markers including CRP, IL-6, sTNF-R1, sTNF-R2, and E-selectin than the matched control group. Men with CHD had significantly higher levels of CRP, IL-6, and VCAM-1, but mean sTNF-R1 and sTNF-R2 levels were not different between the groups. The characteristics did not change substantially when including men and matching controls who needed cardiac revascularization, the secondary endpoint (MEN II). The distributions of genotypes were in Hardy-Weinberg equilibrium both in cases as well as controls $(\mathrm{p}>0.10)$. The genotype frequencies are listed in table 2. Only the distribution of the LGALS2 gene polymorphism was significantly different between female cases in comparison to matched event-free controls. The pairwise linkage disequilibrium (D') and the correlation coefficient between LTA T26N and LTA A252G were 0.99. No correlation was present between the LTA gene polymorphisms and LGALS2 gene polymorphism.

\footnotetext{
Association between LTA and LGALS2 gene polymorphisms and markers of inflammation and cell adhesion molecules

Table 3 shows the age-adjusted levels of the inflammatory markers and cell adhesion molecules (i.e. CRP, IL-6, sTNF-R1, sTNF-R2, VCAM-1, and E-selectin) among the different genotypes. The LTA T26N polymorphism was associated with plasma levels of sTNF-R2 and VCAM-1 in both female and male cases. In addition, LTA T26N polymorphism was significantly associated with IL-6 in men without CHD (table 3a). Similar results were found for the LTA A252G polymorphism, which was also associated with sTNFR-R1 levels in both women as well as men
} 
with CHD (table 3b). The LGALS2 polymorphism was associated with CRP levels in both male and female cases (table 3c). Furthermore, no significant interaction was present between BMI and the gene polymorphisms on the inflammatory markers in cases or controls from both the female and male cohort.

\section{Association between LTA and LGALS2 gene polymorphisms and risk of coronary heart disease}

Table 4 presents the results from unconditional multivariate logistic regression analyses for CHD. The LGALS2 gene variant was inversely associated with a risk for CHD in women (Odds ratio [95\% confidence intervals]: 0.70 [0.50-0.97], $\mathrm{p}=0.03$ ). This effect was independent of cardiovascular risk factors predictive for cardiovascular disease (diabetes, history of hypertension, body mass index, family history of myocardial infarction, HDL-cholesterol, LDLcholesterol, CRP, IL-6, sTNF-R1, sTNF-R2, VCAM-1, and E-selectin). The Odds ratio for CHD in women after adjustment for all these factors was 0.36 [0.22-0.59], $\mathrm{p}<0.001$. This association was not present in men and after pooling the data from both women and men, we found a significant gender interaction between the LGALS2 gene polymorphism and risk of CHD ( $\mathrm{p}$ for interaction $=0.01)$.

\section{DISCUSSION}

In the current large prospective nested case-control study among US women and men, we investigated the relation between LTA gene and LGALS2 gene polymorphisms and levels of inflammatory markers, cell adhesion molecules, and risk of CHD. This study showed significant associations between the polymorphisms of the LTA and LGALS2 gene and markers of inflammation and cell adhesion molecules, but no association was found between LTA gene polymorphisms and risk of CHD in women and men. For the LGALS2 gene polymorphism, we 
found evidence for a significant gender interaction, with a significant association for women but not men with the risk of CHD.

Previous case-control and cross-sectional studies have examined the association between LTA gene polymorphisms and cardiovascular disease, but results are inconsistent. The first study by Ozaki et al[4] described significant associations between the LTA gene polymorphisms and myocardial infarction. However, the authors did not adjust for relevant co-variates including gender and age, and the genotype distributions among the control subjects were not in HardyWeinberg equilibrium. The association between the LTA polymorphisms and CHD was confirmed in another Japanese population[5] and in the family-based European PROCARDIS study [6]. Furthermore, a significant association was found between the LTA T26N genotype and the extent of coronary atherosclerosis in Caucasian patients with angiographically confirmed coronary atherosclerosis[7]. In concordance with the present results, several other studies did not detect an association between LTA polymorphisms and myocardial infarction[8-10] and our findings are in agreement with a recent meta-analysis performed by Clarke and colleagues, which showed no relation between LTA gene polymorphisms and CHD [10]. In contrast to the previous reports included in this meta-analysis, we used unrelated controls selected from the same population as the cases.

Our study showed a significant association between LGALS2 gene polymorphism and reduced risk for CHD in women. However, this association could not be replicated in our male population. This statistical gender interaction might be a true biological interaction, or may reflect differences in cardiovascular risk factors in the male and female study populations. The present study is in concordance with the findings of Ozaki et al[3], who found an association between the LGALS2 gene polymorphism and myocardial infarction. However, this study did not provide any information about gender differences. Other functional studies published so far do not mention differences in LTA secretion between genders, but as shown in table 1, levels of inflammatory 
markers differ between genders and therefore it is possible that LTA has a sex-specific range too. Future studies are needed to investigate whether LTA secretion differs between genders.

Surprisingly, no relation could be found between LTA gene polymorphisms and Creactive protein. LTA is a proinflammatory cytokine through activation of NFkB nuclear protein and previous reports demonstrated a weak, but significant association between LTA gene polymorphism and CRP levels[10;13]. Galectin 2 has been shown to affect LTA expression levels and might therefore influence CRP levels as well. However, the relation between LGALS2 genotype and CRP in the current study is opposite from expected. We cannot exclude the role of chance or some counter regulatory action which we did not capture with the genetic variation in LGALS2. Clearly, further study is needed to confirm or reject the current finding.

Interestingly, we found a significant association between LTA gene polymorphisms and level of sTNF-R2 in both women and men. Lymphotoxin- $\alpha$ is a proinflammatory cytokine that may contribute to atherosclerosis by activation of growth factors, cytokines, and by effecting the synthesis and stimulation of adhesion molecules[4]. Lymphotoxin- $\alpha$, as TNF- $\alpha$, interacts with the soluble TNF receptor 1 and soluble TNF receptor 2. sTNF-R concentrations are increased in patients with infectious diseases and may be useful as an indicator of Lymphotoxin- $\alpha$ induced inflammation[14]. On the other hand, the observed association between LTA gene polymorphisms and inflammatory markers might also represent an effect of the TNF- $\alpha$ gene or other genetic products of the HLA cluster, because the LTA gene is in significant linkage disequilibrium with the TNF- $\alpha$ gene located on chromosome 6 and the HLA cluster[15]. Furthermore, we detected a weak association between VCAM-1 and LTA gene polymorphisms. However, the direction of the associations between VCAM-1 and LTA gene polymorphisms found in the current study were not consistent among the cohorts. In contrast to the males, the variant genotype was associated with lower VCAM-1 levels in the female cases. This might be due to chance considering the borderline significance levels or indicate a true gender difference. Ozaki et al previously demonstrated that variant protein LTA 26A induced an 
increase in VCAM-1 and E-selectin in vascular smooth-muscle cells of the human coronary artery[4]. Elevated expression of adhesion molecules such as VCAM-1 and E-selectin might contribute to the pathogenesis of myocardial infarction, but despite the association between LTA gene polymorphisms and VCAM-1, no relation between LTA gene polymorphisms and CHD could be demonstrated in the present study.

In conclusion, this study demonstrated an association between LTA and LGALS2 gene polymorphisms and markers of inflammation and cell adhesion molecules, but did not detect a significant association between LTA gene polymorphisms and CHD in US men and women. Future studies are needed to replicate the observed association between the LGALS2 gene polymorphism and reduced risk for CHD in women.

\section{ACKNOWLEDGMENTS}

This study has been funded by the Jan Kornelis de Cock foundation (06-05), Groningen, the Netherlands and by the National Institutes of Health (HL35464, CA55075, and HL34594). We gratefully acknowledge Patrice Soule and Hardeep Ranu of the HSPH Molecular Epidemiology Core for genotyping. We would like to thank Alan Paciorek, Helena Ellis, and Jeanne Sparrow for coordinating sample collection and laboratory management, and Lydia Liu for programming review. Dr. F.W. Asselbergs is a research fellow of the Netherlands Heart Foundation (2003T010) and the Dutch Inter University Cardiology Institute Netherlands.

\section{REFERENCES}

1 Libby,P., Ridker,P.M. and Maseri,A. (2002) Inflammation and atherosclerosis. Circulation 105, 1135-1143. 
2 Schreyer,S.A., Vick,C.M. and LeBoeuf,R.C. (2002) Loss of lymphotoxin-alpha but not tumor necrosis factor-alpha reduces atherosclerosis in mice. J Biol.Chem. 277, 1236412368.

3 Ozaki,K., Inoue,K., Sato,H. et al. (2004) Functional variation in LGALS2 confers risk of myocardial infarction and regulates lymphotoxin-alpha secretion in vitro. Nature 429, 72 75.

4 Ozaki,K., Ohnishi,Y., Iida,A. et al. (2002) Functional SNPs in the lymphotoxin-alpha gene that are associated with susceptibility to myocardial infarction. Nat.Genet. 32, 650654.

5 Iwanaga,Y., Ono,K., Takagi,S. et al. (2004) Association analysis between polymorphisms of the lymphotoxin-alpha gene and myocardial infarction in a Japanese population. Atherosclerosis 172, 197-198.

6 (2004) A trio family study showing association of the lymphotoxin-alpha N26 (804A) allele with coronary artery disease. Eur.J.Hum.Genet. 12, 770-774.

7 Laxton,R., Pearce,E., Kyriakou,T. and Ye,S. (2005) Association of the lymphotoxinalpha gene Thr26Asn polymorphism with severity of coronary atherosclerosis. Genes Immun. 6, 539-541.

8 Koch,W., Kastrati,A., Bottiger,C., Mehilli,J., von Beckerath,N. and Schomig,A. (2001) Interleukin-10 and tumor necrosis factor gene polymorphisms and risk of coronary artery disease and myocardial infarction. Atherosclerosis 159, 137-144. 
9 Yamada,A., Ichihara,S., Murase,Y. et al. (2004) Lack of association of polymorphisms of the lymphotoxin alpha gene with myocardial infarction in Japanese. J.Mol.Med. 82, 477483.

10 Clarke,R., Xu,P., Bennett,D. et al. (2006) Lymphotoxin-alpha gene and risk of myocardial infarction in 6,928 cases and 2,712 controls in the ISIS case-control study. PLoS.Genet. 2, e107.

11 Meigs,J.B., Hu,F.B., Rifai,N. and Manson,J.E. (2004) Biomarkers of endothelial dysfunction and risk of type 2 diabetes mellitus. JAMA 291, 1978-1986.

12 Rothman,K.J. (1990) No adjustments are needed for multiple comparisons. Epidemiology $1,43-46$.

13 Suzuki,G., Izumi,S., Hakoda,M. and Takahashi,N. (2004) LTA 252G allele containing haplotype block is associated with high serum C-reactive protein levels. Atherosclerosis 176, 91-94.

14 van der Poll, T., Jansen,J., van Leenen,D. et al. (1993) Release of soluble receptors for tumor necrosis factor in clinical sepsis and experimental endotoxemia. J Infect.Dis. 168, $955-960$.

15 Locksley,R.M., Killeen,N. and Lenardo,M.J. (2001) The TNF and TNF receptor superfamilies: integrating mammalian biology. Cell 104, 487-501. 
$\underline{\text { Table } 1}$ Baseline Characteristics of Women and Men I with incident nonfatal myocardial infarction or fatal coronary heart disease (Cases) and matched event-free Controls.

\begin{tabular}{|c|c|c|c|c|c|c|}
\hline \multirow[t]{3}{*}{ Variable* } & \multicolumn{2}{|c|}{ Women } & \multirow[t]{3}{*}{ P-value } & \multicolumn{2}{|c|}{ Men I } & \multirow[t]{3}{*}{ P-value } \\
\hline & Cases & Controls & & Cases & Controls & \\
\hline & $(n=249)$ & $(n=498)$ & & $(n=266)$ & $(n=522)$ & \\
\hline Age (years) & $60.4 \pm 0.4$ & $60.3 \pm 0.3$ & Matched & $65.2 \pm 8.3$ & $65.1 \pm 8.3$ & Matched \\
\hline Current smoker $(\%)$ & 32.1 & 31.9 & Matched & 12.0 & 12.1 & Matched \\
\hline Caucasians (\%) & 96.1 & 96.5 & 0.64 & 98.1 & 98.2 & 0.42 \\
\hline Diabetes $(\%)$ & 19.7 & 6.6 & $<0.001$ & 9.4 & 4.5 & 0.007 \\
\hline History of Hypertension (\%) & 57.4 & 29.3 & $<0.001$ & 42.1 & 30.9 & 0.002 \\
\hline BMI $\left(\mathrm{kg} / \mathrm{m}^{2}\right)$ & $26.8 \pm 0.4$ & $25.4 \pm 0.2$ & $<0.001$ & $26.2 \pm 0.2$ & $25.7 \pm 0.2$ & 0.06 \\
\hline Family history of MI (\%) & 27.7 & 12.3 & $<0.001$ & 51.5 & 37.3 & $<0.001$ \\
\hline HDL-cholesterol (mg/dL) & $51.7 \pm 0.9$ & $60.3 \pm 0.8$ & $<0.001$ & $42.1 \pm 0.7$ & $45.9 \pm 0.5$ & $<0.001$ \\
\hline$(\mathrm{mmol} / \mathrm{L})$ & $1.32 \pm 0.02$ & $1.55 \pm 0.02$ & & $1.08 \pm 0.02$ & $1.18 \pm 0.01$ & \\
\hline LDL-cholesterol (mg/dL) & $143.0 \pm 2.2$ & $132.3 \pm 1.7$ & $<0.001$ & $135.6 \pm 2.2$ & $126.8 \pm 1.4$ & $<0.001$ \\
\hline$(\mathrm{mmol} / \mathrm{L})$ & $3.67 \pm 0.06$ & $3.39 \pm 0.04$ & & $3.48 \pm 0.06$ & $3.25 \pm 0.04$ & \\
\hline C-reactive protein $(\mathrm{mg} / \mathrm{L})$ & $3.12[1.30-7.50]$ & $2.20[1.00-5.23]$ & $<0.001$ & $1.68[0.76-3.15]$ & $1.08[0.52-2.40]$ & $<0.001$ \\
\hline $\mathrm{Il}-6(\mathrm{pg} / \mathrm{ml})$ & $1.99[1.30-3.04]$ & $1.66[1.16-2.67]$ & 0.002 & $1.86[1.10-3.07]$ & $1.53[0.97-2.88]$ & 0.008 \\
\hline STNF-R1 $(\mathrm{pg} / \mathrm{ml})$ & $1447 \pm 38$ & $1270 \pm 16$ & $<0.001$ & $1514 \pm 31$ & $1504 \pm 23$ & 0.81 \\
\hline STNF-R2 (pg/ml) & $2790 \pm 64$ & $2491 \pm 32$ & $<0.001$ & $2992 \pm 53$ & $2943 \pm 38$ & 0.45 \\
\hline VCAM-1 & $726 \pm 171$ & $703 \pm 157$ & 0.13 & $1364 \pm 331$ & $1311 \pm 318$ & 0.03 \\
\hline E-selectin & $49.4[35.6-63.7]$ & $44.1[31.7-56.8]$ & 0.001 & - & - & - \\
\hline
\end{tabular}

* Continuous variables are presented as mean \pm standard error, except for C-reactive protein, interleukin-6, and E-selectin, which are presented as median [interquartile range]. 
$\underline{\text { Table } 2}$ Genotype distributions among Women, Men I with incident nonfatal myocardial infarction or fatal coronary heart disease, and Men II with incident non-fatal myocardial infarction or fatal coronary heart disease, or underwent coronary artery bypass graft surgery or percutaneous transluminal coronary angioplasty (Cases) and matched event-free Controls.

\begin{tabular}{|c|c|c|c|c|c|c|}
\hline \multirow[t]{2}{*}{ Variable } & \multicolumn{2}{|c|}{ Women } & \multicolumn{2}{|c|}{ Men I } & \multicolumn{2}{|c|}{ Men II } \\
\hline & $\begin{array}{l}\text { Cases } \\
(n=249)\end{array}$ & $\begin{array}{l}\text { Controls } \\
(n=498)\end{array}$ & $\begin{array}{c}\text { Cases } \\
(n=266)\end{array}$ & $\begin{array}{l}\text { Controls } \\
\qquad(n=522)\end{array}$ & $\begin{array}{c}\text { Cases } \\
(n=830)\end{array}$ & $\begin{array}{l}\text { Controls } \\
\qquad(n=1660)\end{array}$ \\
\hline \multicolumn{7}{|c|}{ LTA T26N } \\
\hline $\mathrm{AA}$ & $101(43.9 \%)$ & $208(44.2 \%)$ & $118(47.8 \%)$ & $221(44.5 \%)$ & $384(49.9 \%)$ & $720(46.2 \%)$ \\
\hline $\mathrm{CA}$ & $95(41.3 \%)$ & $213(45.2 \%)$ & $100(40.5 \%)$ & $223(44.9 \%)$ & $304(39.5 \%)$ & $691(44.4 \%)$ \\
\hline $\mathrm{CC}$ & $34(14.8 \%)$ & $50(10.6 \%)$ & $29(11.7 \%)$ & $53(10.7 \%)$ & $81(10.5 \%)$ & $145(9.3 \%)$ \\
\hline P-value* & 0.42 & & 0.67 & & 0.39 & \\
\hline \multicolumn{7}{|c|}{ LTA A $252 \mathrm{G}$} \\
\hline $\mathrm{AA}$ & $103(43.5 \%)$ & $207(44.9 \%)$ & $119(46.5 \%)$ & $223(44.4 \%)$ & $389(49.2 \%)$ & $730(46.0 \%)$ \\
\hline AG & $98(41.4 \%)$ & $199(43.2 \%)$ & $106(41.4 \%)$ & $225(44.8 \%)$ & $320(40.5 \%)$ & $708(44.6 \%)$ \\
\hline GG & $36(15.2 \%)$ & $55(11.9 \%)$ & $31(12.1 \%)$ & $54(10.8 \%)$ & $82(10.4 \%)$ & $148(9.3 \%)$ \\
\hline P-value* & 0.39 & & 0.89 & & 0.46 & \\
\hline \multicolumn{7}{|l|}{ LGALS2 } \\
\hline $\mathrm{CC}$ & $102(43.8 \%)$ & $162(34.8 \%)$ & $72(28.6 \%)$ & $170(33.9 \%)$ & $230(29.5 \%)$ & $506(32.2 \%)$ \\
\hline $\mathrm{CT}$ & $99(42.5 \%)$ & $220(47.3 \%)$ & $133(52.8 \%)$ & $232(46.2 \%)$ & $394(50.5 \%)$ & $749(47.6 \%)$ \\
\hline $\mathrm{TT}$ & $32(13.7 \%)$ & $83(17.9 \%)$ & $47(18.7 \%)$ & $100(19.9 \%)$ & $157(20.1 \%)$ & $319(20.3 \%)$ \\
\hline P-value* & 0.02 & & 0.46 & & 0.41 & \\
\hline
\end{tabular}

* P-value for comparison between cases and controls. 
Table 3a Biomarker levels adjusted for age according to LTA T26N (rs1041981) genotype among women and men. Variables are presented as mean \pm standard error, except for $C$ reactive protein, interleukin-6 and E-selectin, which are presented as geometric mean $[95 \%$ confidence intervals].

\begin{tabular}{|c|c|c|c|c|c|c|}
\hline \multirow{2}{*}{$\begin{array}{l}\text { Cases } \\
\text { Variable }\end{array}$} & \multicolumn{3}{|c|}{ Women } & \multicolumn{3}{|c|}{ Men I } \\
\hline & AA & $\mathrm{CA}$ & $\mathrm{CC}$ & AA & CA & $\mathrm{CC}$ \\
\hline CRP & $2.73[2.21-3.36]$ & $3.46[2.70-4.43]$ & $3.40[2.31-5.01]$ & $1.59[1.30-1.94]$ & 1.66 [1.39-1.99] & $1.61[1.05-2.47]$ \\
\hline IL-6 & $1.99[1.77-2.23]$ & $2.15[1.86-2.48]$ & $1.92[1.50-2.46]$ & $2.36[1.94-2.88]$ & $2.07[1.77-2.43]$ & $2.09[1.51-2.89]$ \\
\hline sTNF-R1 & $1358 \pm 45$ & $1509 \pm 66$ & $1417 \pm 98$ & $1509 \pm 46$ & $1485 \pm 40$ & $1624 \pm 92$ \\
\hline sTNF-R2 & $2568 \pm 74$ & $2960 \pm 106$ & $2726 \pm 151 *$ & $2968 \pm 73$ & $2930 \pm 77$ & $3400 \pm 161 \dagger$ \\
\hline VCAM-1 & $694 \pm 17$ & $769 \pm 680$ & $680 \pm 39 \%$ & $1346 \pm 25$ & $1352 \pm 39$ & $1456 \pm 56 \S$ \\
\hline E-selectin & $46.6[42.6-51.1]$ & $49.8[45.7-54.3]$ & $43.6[38.2-49.7]$ & - & - & - \\
\hline Controls & & Women & & & Men I & \\
\hline Variable & $\mathrm{AA}$ & $\mathrm{CA}$ & $\mathrm{CC}$ & $\mathrm{AA}$ & $\mathrm{CA}$ & $\mathrm{CC}$ \\
\hline CRP & $2.18[1.90-2.51]$ & $2.27[1.92-2.69]$ & $2.01[1.48-2.73]$ & $1.18[1.01-1.38]$ & $1.23[1.05-1.44]$ & $0.96[0.07-1.28]$ \\
\hline IL-6 & 1.75 [1.59-1.92] & $1.90[1.73-2.08]$ & 1.66 [1.39-1.99] & $1.83[1.60-2.09]$ & $1.88[1.68-2.10]$ & $1.50[1.24-1.80] \rrbracket$ \\
\hline sTNF-R1 & $1272 \pm 24$ & $1272 \pm 23$ & $1215 \pm 52$ & $1476 \pm 32$ & $1539 \pm 36$ & $1466 \pm 58$ \\
\hline sTNF-R2 & $2493 \pm 45$ & $2503 \pm 49$ & $2426 \pm 100$ & $2931 \pm 54$ & $2953 \pm 51$ & $2816 \pm 118$ \\
\hline VCAM-1 & $715 \pm 12$ & $694 \pm 13$ & $695 \pm 29$ & $1303 \pm 19$ & $1325 \pm 22$ & $1234 \pm 37 \|$ \\
\hline E-selectin & 41.4 [39.1-43.9] & $43.8[41.4-46.3]$ & $42.5[37.6-48.1]$ & - & - & - \\
\hline
\end{tabular}

*: Additive model: $\mathrm{P}=0.011$; Dominant model $\mathrm{P}=0.005$; Recessive model $\mathrm{P}=0.860$

$\dagger$ : Additive model: $\mathrm{P}=0.029$; Dominant model $\mathrm{P}=0.952$; Recessive model: $\mathrm{P}=0.009$

f: Additive model: $\mathrm{P}=0.018$; Dominant model $\mathrm{P}=0.050$; Recessive model: $\mathrm{P}=0.728$

$\S$ : Additive model: $\mathrm{P}=0.194$; Dominant model $\mathrm{P}=0.471$; Recessive model: $\mathrm{P}=0.076$

ף: Additive model: $\mathrm{P}=0.103$; Dominant model $\mathrm{P}=0.847$; Recessive model: $\mathrm{P}=0.038$

$\|$ : Additive model: $\mathrm{P}=0.102$; Dominant model $\mathrm{P}=0.865$; Recessive model: $\mathrm{P}=0.042$ 
Table 3b Biomarker levels adjusted for age according to LTA A252G (rs909253) genotype among women and men.

\begin{tabular}{|c|c|c|c|c|c|c|}
\hline \multirow{2}{*}{$\begin{array}{l}\text { Cases } \\
\text { Variable }\end{array}$} & \multicolumn{3}{|c|}{ Women } & \multicolumn{3}{|c|}{ Men I } \\
\hline & AA & $\mathrm{AG}$ & GG & AA & $\mathrm{AG}$ & GG \\
\hline CRP & $2.63[2.12-3.26]$ & $3.62[2.84-4.62]$ & $3.22[2.17-4.77]$ & $1.62[1.33-1.98]$ & $1.64[1.38-1.94]$ & $1.49[0.99-2.24]$ \\
\hline IL-6 & $1.97[1.75-2.20]$ & $2.17[1.90-2.48]$ & $1.87[1.45-2.40]$ & $2.27[1.87-2.76]$ & $2.08[1.77-2.44]$ & $1.96[1.43-2.67]$ \\
\hline sTNF-R1 & $1344 \pm 44$ & $1562 \pm 68$ & $1407 \pm 93 *$ & $1493 \pm 43$ & $1497 \pm 39$ & $1604 \pm 87$ \\
\hline sTNF-R2 & $2553 \pm 72$ & $3051 \pm 117$ & $2711 \pm 144 \dagger$ & $2933 \pm 73$ & $2929 \pm 74$ & $3332 \pm 157 \ddagger$ \\
\hline VCAM-1 & $694 \pm 17$ & $776 \pm 21$ & $696 \pm 40 \S$ & $1340 \pm 25$ & $1350 \pm 36$ & $1457 \pm 539$ \\
\hline E-selectin & $46.3[42.5-50.5]$ & $50.0[45.8-54.6]$ & $43.6[38.4-49.4]$ & - & - & - \\
\hline Controls & & Women & & & Men I & \\
\hline Variable & AA & $\mathrm{AG}$ & GG & AA & $\mathrm{AG}$ & GG \\
\hline CRP & $2.17[1.88-2.50]$ & $2.35[1.98-2.80]$ & $1.92[1.46-2.54]$ & $1.19[1.02-1.40]$ & $1.22[1.05-1.43]$ & $0.95[0.72-1.27]$ \\
\hline IL-6 & 1.75 [1.59-1.93] & $1.93[1.76-2.13]$ & $1.67[1.41-1.99]$ & $1.83[1.61-2.09]$ & $1.89[1.69-2.10]$ & $1.51[1.26-1.81] \|$ \\
\hline sTNF-R1 & $1268 \pm 24$ & $1277 \pm 24$ & $1261 \pm 52$ & $1481 \pm 31$ & $1535 \pm 36$ & $1479 \pm 57$ \\
\hline sTNF-R2 & $2492 \pm 45$ & $2503 \pm 52$ & $2553 \pm 106$ & $2950 \pm 54$ & $2956 \pm 52$ & $2895 \pm 121$ \\
\hline VCAM-1 & $715 \pm 12$ & $688 \pm 13$ & $717 \pm 32$ & $1307 \pm 19$ & $1328 \pm 22$ & $1255 \pm 41$ \\
\hline E-selectin & $42.2[39.7-44.8]$ & $43.4[40.9-46.0]$ & $42.9[37.8-48.7]$ & - & - & - \\
\hline
\end{tabular}

*: Additive model: $\mathrm{P}=0.028$; Dominant model: $\mathrm{P}=0.014$; Recessive model: $\mathrm{P}=0.676$

$\dagger$ : Additive model: $\mathrm{P}=0.002$; Dominant model: $\mathrm{P}=0.001$; Recessive model: $\mathrm{P}=0.606$

f: Additive model: $\mathrm{P}=0.056$; Dominant model: $\mathrm{P}=0.384$; Recessive model: $\mathrm{P}=0.016$

$\S$ : Additive model: $\mathrm{P}=0.009$; Dominant model: $\mathrm{P}=0.017$; Recessive model: $\mathrm{P}=0.342$.

9: Additive model: $\mathrm{P}=0.128$; Dominant model: $\mathrm{P}=0.379$; Recessive model: $\mathrm{P}=0.049$

$\|$ : Additive model: $\mathrm{P}=0.111$; Dominant model: $\mathrm{P}=0.872$; Recessive model: $\mathrm{P}=0.042$ 
$\underline{\text { Table 3c Biomarker levels adjusted for age according to LGALS2 (rs7291467) genotype }}$ among women and men.

\begin{tabular}{|c|c|c|c|c|c|c|}
\hline \multirow{2}{*}{$\begin{array}{l}\text { Cases } \\
\text { Variable }\end{array}$} & \multicolumn{3}{|c|}{ Women } & \multicolumn{3}{|c|}{ Men I } \\
\hline & $\mathrm{CC}$ & CT & TT & $\mathrm{CC}$ & $\mathrm{CT}$ & TT \\
\hline CRP & $2.61[2.06-3.29]$ & $3.88[3.15-4.78]$ & $2.73[1.80-4.14]^{*}$ & $1.26[1.02-1.56]$ & $1.71[1.42-2.05]$ & $1.84[1.37-2.47] \dagger$ \\
\hline IL-6 & $2.09[1.82-2.40]$ & $2.14[1.90-2.40]$ & $1.97[1.49-2.60]$ & $1.81[1.54-2.12]$ & $2.36[1.97-2.82]$ & $2.01[1.55-2.59]$ \\
\hline sTNF-R1 & $1426 \pm 58$ & $1447 \pm 60$ & $1468 \pm 103$ & $1478 \pm 51$ & $1490 \pm 38$ & $1557 \pm 63$ \\
\hline sTNF-R2 & $2765 \pm 105$ & $2802 \pm 91$ & $2847 \pm 177$ & $3017 \pm 94$ & $2920 \pm 70$ & $3071 \pm 94$ \\
\hline VCAM-1 & $721 \pm 20$ & $736 \pm 22$ & $702 \pm 31$ & $1412 \pm 36$ & $1329 \pm 26$ & $1392 \pm 57$ \\
\hline E-selectin & $46.1[42.3-50.1]$ & $48.8[44.5-53.4]$ & $51.0[44.1-59.1]$ & - & - & - \\
\hline Controls & Women & & & & Men I & \\
\hline Variable & $\mathrm{CC}$ & CT & $\mathrm{TT}$ & $\mathrm{CC}$ & CT & TT \\
\hline CRP & $2.12[1.80-2.49]$ & $2.15[1.83-2.54]$ & $2.35[1.87-2.94]$ & $1.27[1.06-1.52]$ & $1.16[1.01-1.34]$ & $1.03[0.80-1.34]$ \\
\hline IL-6 & 1.79 [1.63-1.98] & $1.85[1.67-2.04]$ & $1.75[1.52-2.01]$ & $1.92[1.68-2.20]$ & 1.70 [1.54-1.88] & $1.94[1.56-2.41]$ \\
\hline sTNF-R1 & $1250 \pm 25$ & $1273 \pm 24$ & $1311 \pm 38$ & $1513 \pm 34$ & $1494 \pm 34$ & $1512 \pm 56$ \\
\hline sTNF-R2 & $2453 \pm 50$ & $2513 \pm 50$ & $2525 \pm 67$ & $3000 \pm 64$ & $2870 \pm 51$ & $3006 \pm 82$ \\
\hline VCAM-1 & $712 \pm 16$ & $698 \pm 11$ & $692 \pm 23$ & $1316 \pm 27$ & $1297 \pm 19$ & $1332 \pm 26$ \\
\hline E-selectin & $43.2[40.5-46.2]$ & $41.5[39.1-44.0]$ & $46.5[42.5-50.8]$ & - & - & - \\
\hline
\end{tabular}

*: Additive model: $\mathrm{P}=0.035$; Dominant model: $\mathrm{P}=0.041$; Recessive model: $\mathrm{P}=0.507$

$\dagger$ : Additive model: $\mathrm{P}=0.051$; Dominant model: $\mathrm{P}=0.017$; Recessive model: $\mathrm{P}=0.281$ 
$\underline{\text { Table } 4}$ Unconditional logistic regression analysis among Women, Men I with incident nonfatal myocardial infarction or fatal coronary heart disease, and Men II with incident non-fatal myocardial infarction or fatal coronary heart disease, or underwent coronary artery bypass graft surgery or percutaneous transluminal coronary angioplasty (Cases) and matched event-free Controls.

\begin{tabular}{|c|c|c|c|c|}
\hline & $\begin{array}{c}\text { Women } \\
\text { Odds ratio }(95 \% \mathrm{CI})\end{array}$ & $\begin{array}{c}\text { Men I } \\
\text { Odds ratio }(95 \% \mathrm{CI})\end{array}$ & $\begin{array}{c}\text { Men II } \\
\text { Odds ratio }(95 \% \mathrm{CI})\end{array}$ & $\begin{array}{c}\text { Pooled } \\
\text { (women and men I) } \\
\text { Odds ratio }(95 \% \mathrm{CI})\end{array}$ \\
\hline \multicolumn{5}{|l|}{ LTA T26N } \\
\hline Additive & $1.08[0.85-1.36]$ & $0.95[0.76-1.20]$ & $0.94[0.82-1.07]$ & $0.99[0.84-1.17]$ \\
\hline Dominant & $0.98[0.71-1.36]$ & $0.87[0.64-1.82]$ & $0.86[0.72-1.02]$ & $0.92[0.74-1.15]$ \\
\hline Recessive & $1.42[0.88-2.28]$ & $1.13[0.70-1.84]$ & $1.15[0.86-1.54]$ & $1.20[0.86-1.67]$ \\
\hline \multicolumn{5}{|c|}{ LTA A252G } \\
\hline Additive & $1.08[0.86-1.36]$ & $0.99[0.79-1.24]$ & $0.95[0.83-1.08]$ & $1.03[0.87-1.20]$ \\
\hline Dominant & $1.04[0.75-1.43]$ & $0.92[0.68-1.25]$ & $0.88[0.74-1.04]$ & $0.96[0.77-1.19]$ \\
\hline Recessive & $1.29[0.81-2.05]$ & $1.15[0.72-1.85]$ & $1.13[0.85-1.50]$ & $1.15[0.84-1.59]$ \\
\hline \multicolumn{5}{|l|}{ LGALS2 } \\
\hline Additive & $0.77[0.61-0.97]^{*}$ & $1.09[0.88-1.35]$ & $1.05[0.93-1.19]$ & $0.94[0.80-1.10]$ \\
\hline Dominant & $0.70[0.50-0.97] \dagger$ & $1.29[0.92-1.79]$ & $1.14[0.94-1.37]$ & $0.94[0.75-1.19]$ \\
\hline Recessive & $0.72[0.46-1.13]$ & $0.93[0.63-1.37]$ & $1.00[0.80-1.23]$ & $0.87[0.64-1.17]$ \\
\hline
\end{tabular}

